Cuadernos de Historia del Derecho

ISSN: $1133-7613$

http://dx.doi.org/10.5209/CUHD.61874

\title{
Dos procesos de la Corte del Vicario de Barcelona: el asalto a Joan de Palomar (1426)
}

\section{Daniel Álvarez Gómez ${ }^{1}$}

Recibido: 10 de julio de 2017 / Aceptado: 07 de septiembre de 2017

Resumen. A partir de dos procesos en la Corte del vicario de Barcelona, en 1426, de los que se conservan sendas copias en el Archivo de la Corona de Aragón, se estudia un episodio de la vida del jurista Narcís de Sant Dionís. De su entorno familiar parte una agresión contra Joan de Palomar porque este había aceptado la auditoría de cuentas de la Diputación tras quedar vacante por la destitución previa de Sant Dionís. Los procesos son instruidos contra elementos mantenidos por Sant Dionís o cercanos a él, como su sobrino el vicario homónimo de Gerona, responsable del ataque.

Palabras clave: Narcís de Sant Dionís; Joan de Palomar; Corte del vicario; Paz y Tregua; Diputación; auditoría de cuentas; ataque.

\section{[en] Two Cases of the Court of the Vicar of Barcelona: the assault on Joan of Palomar (1426)}

\begin{abstract}
From two proceedings in the Barcelona's Vicar's court, in 1426, of which copies are kept in the Archive of the Crown of Aragon, an episode of the life of the jurist Narcís de Sant Dionís is studied. From his family surroundings an aggression occurs against Joan of Palomar because Palomar had accepted the audit of accounts of the Diputación after being vacant by the previous destitution of Sant Dionís. The cases are instructed against elements maintained by or close to Sant Dionís, such as his nephew, the homonymous vicar of Gerona, held responsible for the attack.

Key words: Narcís de Sant Dionís; Joan of Palomar; Court of the vicar; Peace and Truce; Diputación; audit of accounts; attack.
\end{abstract}

\section{[fr] Deux procès de la Cour du Vicaire de Barcelone: l'assaut contre Joan de Palomar (1426)}

Résumé. Suivant deux procès à la Cour du Vicaire de Barcelone, en 1426, dont des copies respectives sont conservés dans les archives de la Couronne d'Aragon, un épisode de la vie du juriste Narcís Sant Dionis est ici étudié. Parmi son environnement familial, une agression contre Joan de Palomar a commencé parce qu'il avait accepté l'audit des comptes de la Diputación après être devenu vacant en raison du licenciement préalable de Sant Dionís. Les procédures sont instruites contre des éléments entretenus par Sant Dionís ou près de lui, comme son neveu le vicaire du même nom, responsable de l'attaque. Mots clé : Narcís de Sant Dionís; Joan de Palomar; Cour Vicaire; Paix et Trêve; Députation; audit des comptes; attaque.

\footnotetext{
Departament de Filologia Llatina. Universitat de Barcelona
} daniel_alvarez_23@hotmail.com 
Sumario: 1. Los dos volúmenes. 2. Antecedentes. 3. El ataque contra Joan de Palomar (1426). 4.Primer proceso: G-232. 4.1. Interrogatorios a Narcís Vidal. 4.2. Interrogatorios a Pere Vidal. 4.3. Careo entre los hermanos Vidal. 4.4. Ulteriores diligencias: el 'guiatge' y otros testimonios. 4.5. Consulta jurídica sobre el 'guiatge' y parecer de Bonanat Pere. 4.6. Testimonios de la comitiva de Joan de Palomar. 4.7. Desestimación del 'guiatge' y cambio de jueces en la Corte del vicario. 4.8. Último interrogatorio a Narcís Vidal y sentencia. 5. Segundo proceso: G-193-4. 5.1. Cartas citatorias y respuesta del vicario Sant Dionís. 5.2. Intervención del abogado Dalmau de Sant Dionís. 5.3. Expulsión de Paz y Tregua. 5.4. Duplicación de la multa y testimonios de la Diputación. 5.5. Sentencia y desenlace. 6. Conclusión. 7.Bibliografía. 7.1. Fuentes manuscritas o gráficas. 7.2. Bibliografía impresa.

Cómo citar: D. Álvarez Gómez (2018). «Dos procesos de la Corte del Vicario de Barcelona: el asalto a Joan de Palomar (1426)», Cuadernos de Historia del Derecho, XXV, 2018, 45-67.

\section{Los dos volúmenes}

La presente contribución da cuenta de las actuales investigaciones alrededor de las actas notariales de dos juicios celebrados en la Corte del máximo oficial real de Barcelona, el vicario real (llamado veguer), a la sazón Guillem de Bordils, durante los primeros meses de 1427. Se trata de dos volúmenes conservados en la sección Judicials de la Generalitat en el Archivo de la Corona de Aragón (ACA), en relativo buen estado.

El primer proceso, ACA, Generalitat, serie G, 232 (en adelante G-232), se compone, al parecer (la encuadernación dificulta el examen detallado), de seis cuadernos en pergamino, los cuatro primeros de 12 folios cada uno, menos el quinto y el sexto, que son 10 y 7 folios respectivamente: en total 65. Excepto el primero, todos los cuadernos se numeraron con letras romanas, en las mismas caligrafía y tinta del texto manuscrito, en el margen superior izquierdo de su primer folio: II $^{\mathrm{a}}$ (f. 13r), III ${ }^{\mathrm{a}}$ (f. 25r), IIII ${ }^{\mathrm{a}}(37 \mathrm{r}), \mathrm{V}^{\mathrm{a}}$ (49r), VI ${ }^{\mathrm{a}}$ (59r). Puede haber sido reencuadernado en tiempos del archivero Bofarull (s. XIX), aunque quizá conservando sus cubiertas originales, que son de piel y lucen el sello de la Diputación, un escudo en rombo con la cruz de San Jorge, descolorida, dentro de una figura trebolada de cuatro hojas. Tiene dos broches metálicos con bridas, en desuso. Los folios presentan estas medidas: c. $25^{\prime} 7 \times 18 \mathrm{~cm}$, escritos a doble cara, con caja de c. $17 \times 11^{\prime} 2 \mathrm{~cm}$. Cada página contiene una media de 30 líneas bien visibles en todo el manuscrito. El tamaño de escritura es de $2 \mathrm{~mm}$, del tipo gótica cursiva. Muestra escasas correcciones, de la misma mano. Hay numeración arábiga a lápiz posterior, en el extremo superior derecho.

El segundo proceso, ACA, Generalitat, serie G, 193, 4 (en adelante G-193-4), se compone de 26 cuadernos en papel de 12 folios cada uno, menos el segundo (ff. numerados 12-21), de 10, el vigésimo (ff. numerados 226-235), de 10, y el último (f. numerado 296), de 8 (añadido especialmente por el copista y notario para fechar y dar fe de su labor). En total suman 304 folios, estando el primero y los 7 últimos sin numerar: I-296-VII. El tamaño del folio es c. $22^{\prime} 5 \times 15 \mathrm{~cm}$. No hay numeración de cuadernos ni reclamos. Su cubierta, ahora suelta y mermada en su parte superior, es un acto jurídico en pergamino de 1424 en presencia del mismo Guillem de Bordils, el cual ha sido reutilizado y en su verso, a modo de tapa exterior, se ha escrito una descripción sucinta del proceso de 1427 que finalmente contiene. Todos los folios 
están escritos a doble cara, menos el primero, donde únicamente se ha registrado en la parte superior del recto el término «Translatum», y solo el recto del f. numerado 296 (en realidad el 297); el verso y el resto de folios del último cuaderno y del manuscrito están en blanco. La caja de escritura es c. 10x16 cm, aunque oscila en $1 \mathrm{~cm}$. La numeración es posterior, en el extremo inferior derecho, arábiga y a lápiz; cada página ronda las 12 líneas. El tamaño de escritura es de $2 \mathrm{~mm}$, del tipo gótica cursiva. Muestra escasas correcciones, de la misma mano, a veces en tinta más clara. El borrado de la escritura dificulta mucho la lectura de primeras líneas, en algunos folios, a veces incluso hasta la mitad de la página.

Se trata de dos copias de Antoni Desvern, el mismo notario y escribano de la Corte del vicario que anotó los originales en ejercicio de su cargo. Deja testimonio de su copia el 4 de noviembre de 1428 en el último folio de ambos con parecidos términos y concluye con su sello notarial ${ }^{2}$. Los dos volúmenes contienen, en definitiva, los juicios celebrados contra inculpados en un único crimen, el ataque con bastones y arma blanca, en las cercanías de la plaza sant Jaume de Barcelona, contra Joan de Palomar, diácono de la sede de la ciudad y canónigo de Gerona, en diciembre de 1426. Este último había sido escogido un año antes oidor de cuentas de la Diputación y venía a cubrir la vacante que dejó la anulación de la elección para el mismo cargo de un canónigo de Barcelona y Gerona, Narcís de Sant Dionís. Los procesos investigan y juzgan a diversos hombres del entorno de Sant Dionís, como actores de dicho asalto.

$\mathrm{El}$ archivo de la Corte del vicario, contenido en parte en el AHCB, no parece conservar los originales de dichos procesos ${ }^{3}$. Tampoco en ACA, hasta el momento, se ha encontrado rastro de ellos. Se trabaja pues con dos copias al parecer fieles, si se da crédito al copista, Desvern, responsable también de los originales extraviados. Hay muestras, sin embargo, de lecturas apresuradas y erróneas, sin sentido, especialmente en G-193-4. En este manuscrito asimismo parece haber reticencias provocadas por una censura propia, que deja algún párrafo sin concluir.

\section{Antecedentes}

Narcís de Sant Dionís, clérigo gerundense y doctor en derecho civil, es el autor del Compendium de toda la legislación catalana aprobada en Cortes Generales, escrito en la década de 1420 y acaso principios de la siguiente. Probablemente hijo del juez real homónimo del s. XIV, era hermano del también jurista Dalmau de Sant Dionís, cuyo hijo, el caballero Narcís de Sant Dionís, fue vicario de Gerona en las fechas del

\footnotetext{
ACA, Generalitat, serie G, 232, ff. 65r-v: «Presens translatum in pergameneis scriptum /65v/ et translatatum in quo sunt scripte sexaginta quinque folee computata presenti fuit abstractum a quodam originali processu inquisicionis facto in posse mei Anthonii dez Vern notarii et scriptoris iurati curie honorabilis uicarii Barchinone et cum dicto suo originali ueridice comprobatum in quorum fidem et testimonium ego dictus notarius et scriptor iuratus hic me propria manu subscribo die uidelicet quarta mensis nouembris anno a natiuitate domini millesimo CCCC uicesimo octauo et hoc meum solitum artis notarie sic appono Sig+num». En ACA, Generalitat, serie G, 193, 4, f. 296r, solo varía significativamente el principio (entre corchetes, la restitución de dos pasajes de muy difícil lectura): «Presens translatum in papiri [scriptum in quo sunt scripte] ducenta nonaginta quinque folee [non computata presenti] fuit translatum a quodam originali processu facto in posse mei Anthonii dez Vern notarii et scritporis iurati Curie honorabilis uicarii Barchinone [...]».

3 Se ha buscado sin éxito en AHCB, Cúria del veguer i del Corregidor, Processos 36, caixes 13 i 14; y en AHCB, Cúria del veguer i del Corregidor, Sententiarum 1-4.
} 
atentado a Palomar, y seguramente cerebro del mismo. Otras familias emparentadas con estos Sant Dionís eran los Sarriera y los Santceloni ${ }^{4}$.

El clérigo Sant Dionís participó en política y fue elegido oidor de cuentas por el brazo eclesiástico para los trienios de 1416-1419, 1425-1428 y 1440-1443. En el segundo, sin embargo, no llegó a jurar el cargo, porque el procurador del General, Bartomeu Ripoll, abrió una causa contra su elección, arguyendo ilegalidad, aunque la documentación estudiada no arroje luz sobre el por qués. La Diputación destituyó a Sant Dionís y decidió proceder a una nueva cooptación, que recayó en el canónigo de Barcelona, Joan de Palomar, cercano a Felip de Malla, el diputado recién elegido para el nuevo trienio de 1425-1428, por el brazo eclesiástico. El 30 de diciembre Palomar aceptó desde Játiva su elección y juró su cargo el 26 de febrero de $1426^{6}$.

Probablemente a finales del mismo 1425, Sant Dionís apeló al rey, que se encontraba en Valencia, contra su destitución. Se desconoce hasta el momento documentación directa que dé cuenta de la apelación. La Diputación se desempeñó airosamente desde Barcelona mediante su procurador Bartomeu Ripoll, entre otros7. Hacia abril y mayo de 1426 probablemente la apelación fue desestimada ${ }^{8}$.

\section{El ataque contra Joan de Palomar (1426)}

Sin duda disconforme con el resultado, Narcís de Sant Dionís o, en cualquier caso, su entorno más cercano, pensó vengarse mediante una acción criminal. Cuanto sabemos de la misma proviene de los procesos instruidos más tarde, especialmente del

Edición crítica del Compendium en Sant Dionís (2016), con una semblanza del personaje y su árbol genealógico (pp. 15-24). Cabe tener presente la reciente tesis de Rexach (2015, passim y p. 1532). Sant Dionís desarrolló una carrera eclesiástica medianamente notable: pasó por el arcedianato de Ribagorza y por el de Besalú y fue canónigo de Lérida, Gerona y Barcelona, además de vicario de las dos últimas sedes. Resulta ser también el tío abuelo del obispo de Siracusa Gabriel Dalmau de Sant Dionís (hijo este del caballero Narcís de Sant Dionís), mecenas de cierta relevancia en el ámbito siciliano del cambio de siglo al XVI (aporté información recabada alrededor del personaje en Álvarez, 2015²). Los Sant Dionís fueron asimismo una familia gerundense cercana a la monarquía, a la que defendieron durante la Guerra Civil catalana.

$5 \quad$ No se colige nada de LQS (pp. 27-28), libro que contiene la normativa de tipo orgánico (no Constituciones Generales) aprobada a finales de agosto de 1413 para regular la Diputación, y que debió de regir también en este asunto. Debe pensarse, sin embargo, que la cooptación de Sant Dionís infringía Capítulos de Cortes según se expresa en albarán de la Diputación de 4 de febrero de 1426 a Palomar (ACA, Generalitat, Cauteles i albarans, N-510, f. 42r), y considerando que Ripoll, quien instruía el caso, había sido nombrado procurador del General para velar por la legislación general (Constituciones y Capítulos), en virtud de la Constitución de 1422 Lo fruït de les lleis (caravyc XIII, pp. 414-415; Sans i Travé, 1994, p. 39).

6 Se ha tratado este asunto en el volumen de Sant Dionís (2016), que se deriva sucintamente de Álvarez (2015²), donde se aporta un apéndice con documentos transcritos. Sant Dionís había sido también elegido miembro de una comisión de seis inquisidores para velar por las Constituciones, en las Cortes de Sant Cugat-Tortosa (1420: caravyc XII, pp. 276; en 1422 es remunerado: caravyc XVIII, pp. 16-22), cuerpo que no parece que fuera confirmado en las de Tortosa-Barcelona (1422: caravyc XIII, pp. 391, 394, 420), cuando sí se aprobó la Constitución antedicha Lo fruït de les lleis; y fue escogido compilador de la nova Compilació junto con Francesc Basset, de la que nace su Compendium. Sobre Joan de Palomar véase al menos Elías de Tejada (1950, pp. 257-267). Palomar destacaría más tarde en el concilio de Basilea (De civili dominio clericorum, Mansi, XXIX, col. 1105-1168; y Mansi, XXX, col. 475-485). Sobre Felip de Malla, véase Perarnau (1978).

7 Sans i Travé (1994, p. 48). ACA, Generalitat, Escrivania Major, lletres trameses, N-641, ff. 66v-67v, 28 de enero de 1426 .

8 Carta de la Diputación a Ramon dez Papiol, otro de sus representantes, del 13 de abril de 1426: ACA, Generalitat, Escrivania Major, lletres trameses, N-641, f. 112v. 
primero. Damos por consiguiente un resumen breve del ataque a Joan de Palomar para pasar a los detalles contenidos en la instrucción antedicha.

A finales del mismo año de 1426, el canónigo Sant Dionís viajó a Gerona al entierro de un hermano suyo ${ }^{9}$ en compañía de su doméstico Pere Vidal, y sus sobrinos Bernat Sarriera, hijo de Arnau Sarriera, y Felip de Santceloni, seguramente marido de Joanota Pinós e hijo de Francesca Sant Dionís ${ }^{10}$. Otro de sus sobrinos, el vicario de Gerona, Narcís de Sant Dionís, tramó entonces con Bernat Sarriera propinar una paliza ('abastonament') o acaso una agresión de mayor envergadura (no queda nunca del todo claro si con la intención de cometer homicidio) contra Joan de Palomar para la vigilia de Navidad (la noche del 24 de diciembre). Los motivos de la acción eran la descortesía en que había incurrido Palomar al aceptar la vacante auditoría de cuentas de la Diputación.

La segunda quincena de diciembre de 1426 todos los hermanos Vidal se encontraron en Barcelona: además de Pere, el doméstico de Sant Dionís, el barbero Francesc Vidal, llamado Franci (que ya estaba en la ciudad)"1, y Narcís Vidal, zapatero, el menor, que contaba entre 21 y 24 años. Estos dos últimos trabajaban en comercios de Barcelona. Sirvió como lugar de encuentro la casa del mismo Narcís de Sant Dionís, canónigo, que sin haber sido localizada se puede suponer que se situaba no muy lejos de la casa de la Diputación. Bernat Sarriera llegó a Barcelona el 24 de diciembre con dos campesinos del Ampurdán y durante la noche se reunieron, con Francesc y Narcís Vidal, en la Plaça Nova, portando espadas, lanzas y bastones. Cuando tocaban maitines, se pusieron al acecho, en diferentes posiciones, en una esquina entre el antiguo call (la judería) y la catedral. Cuando Juan de Palomar, alrededor de las dos de la madrugada, pasó por el lugar en compañía de sus domésticos y de un mercader, Juan de Pallaga, el grupo comandado por Bernat Sarriera los asaltó, apagando los blandones que llevaban; golpearon a Palomar varias veces. El canónigo fue herido. A pesar del éxito del asalto, que sorprendió completamente a la comitiva de Palomar, el clérigo gritó «viafós!»" varias veces y pudo escapar a la carrera en dirección a la catedral, donde finalmente entró. Allí le vendaron la cabeza, que sangraba de una contusión, aunque de poca importancia. Seguidamente asistió a maitines y más tarde a vísperas.

G-232, f. 7v. Considerando que Dalmau de Sant Dionís testó en 1432, y aparece activo en el segundo proceso, se trata de otro, quizá Bernat de Bordils, alias de Sant Dionís (véase Sant Dionís, 2016, pp. 15 y ss.).

10 Los Santceloni y los Sarriera emparentaron con los Sant Dionís en las hijas del Narcís de Sant Dionís del XIV: Francesca por un lado; y Auda y Margarida por el otro. Hubo un Felip Francesc de Santceloni, hijo de Francesc de Santceloni y de Francesca Sant Dionís, hija del Narcís de Sant Dionís del XIV, que podría llegar a identificarse con él. En cuanto a Bernat Sarriera, en el segundo proceso (G-193-4), se presenta muy claramente y repetides veces su parentesco con su tío el clérigo Sant Dionís: el padre de Bernat, Arnau Sarriera (sobre esta rama de esta família, vid. Guilleré, 2005), casó con una hermana de Narcís de Sant Dionís. Esta no puede ser otra que Margarida de Sant Dionís, hija del Narcís de Sant Dionís juez real de Pedro III (vid. Sant Dionís, 2016 , pp. 14-26; Rexach, 2015, p. 1534): esta ligazón familiar coloca al canónigo Sant Dionís, autor del Compendium, en el árbol genealógico del siglo XIV, sobre lo cual aún hay dudas, aunque puede darse por seguro que fuera hijo del otro Sant Dionís, el juez real. Cf. Rexach (2015, p. 581 n. 1498; pp. 1532-1533), si bien no se especifica el documento que prueba la filiación.

11 Franci Vidal parece que se halla presente en el testamento de un sobrino nieto de Narcís de Sant Dionís, el 1432, Antoni Francesc de Sant Dionís (Sans i Travé, 2005, doc. 836). En cuanto a Pere Vidal, figura un homónimo en el testamento del clérigo Narcís de Sant Dionís en 1458, aunque como presbítero beneficiado en la catedral de Barcelona (Álvarez, 2012, p. 246).

12 Esta voz o «Via fora» eran las usadas para llamar a sometent. Vid. Ferro (1999, pp. 77-81). 


\section{Primer proceso: G-232}

Según especifica el acta inicial del vicario de Barcelona, Guillem de Bordils ${ }^{13}$, se presentó una denuncia por acción criminal contra Bernat Sarriera y los hermanos Vidal y se procedió de oficio a la investigación. Al parecer, sólo dos de ellos, que no huyeron de la capital condal, Narcís y Pere Vidal, fueron detenidos por alguaciles (capdeguaites), sucesivamente, el 6 de febrero de 1427, y se les interrogó en la propia Diputación en primera instancia, entre el 7 y el 10 del mismo mes.

El 10 de febrero de 1427 se inició un juicio, en la Corte del vicario, contra Pere y Narcís Vidal, si bien el proceso se centra especialmente en este último. Acometía la instrucción el juez Guillem Perayerii, ciudadano de Barcelona ${ }^{14}$. Se acusaba a los antedichos de ponerse en aguayt (al acecho) ${ }^{15}$, con algunos cómplices, cerca de la Catedral de Barcelona, para atacar a la comitiva de Palomar, que avanzaba en modo reverente ${ }^{16}$. Habían pues infringido la inmunidad eclesiástica, además de la Lex Cornelia de Sicariis, ya que se da a entender que tenían propósito de matar a Palomar, y la Lex Iulia maiestatis, puesto que aquel era también oficial del rey y oidor de cuentas de la Diputación ${ }^{17}$. Se constituían Antoni de Sori como procurador fiscal y Antoni Desvern como notario del proceso ${ }^{18}$.

\subsection{Interrogatorios a Narcís Vidal}

Se procedió entonces a interrogar a Narcís Vidal, asistido por su procurador, Guillem Vidal, acaso un familiar, si bien nada se afirma al respecto ni en este ni en el proceso subsiguiente. Adujo Narcís Vidal que ya se le interrogó en la Diputación y por lo tanto le fueron leídos dichos interrogatorios, de 7, 8 y 10 de febrero, cuatro en total, que se insertan en el proceso.

En el primer interrogatorio refiere ante todo su detención, llevada a cabo por un alguacil y dos de los diputados del General de aquel trienio (del cual había sido apea-

13 Era vicario ya en 1422, cuando en su ausencia su hijo Bernat de Bordils pretendía ejercer como tal, a pesar de la oposición del Consell de Cent de Barcelona (asiento de 12 de octubre, Llibre del Consell, 02.01/B.I-29, f. 21v). Véase otra perspectiva de este asunto en Perarnau (1978, p. 150).

14 Guillem Perayerii figura con la forma latina de su nombre como jurisperito y ciudadano barcelonés en un interrogatorio en las Cortes de Barcelona de 1431-1434 (caravyc XVIII, p. 317). No es deducible claramente el apellido original y parece descartarse «Peraire», como en una publicación anterior propusimos, puesto que este en latín sería «Parator».

15 Cabe recordar los Usatges correspondientes: Si quis se miserit in aguayt y similares. Vid. Valls i Taberner; Abadal y Vinyals (1985).

16 «[...] cum duobus brandonibus siue brandons accensis cum suo abitu clericali capaque canonicali honesto modo cum suis seruitoribus faceret ad dictam Sedem Barchinonenses pro interessendo in dictis matutinis et aliis diuinis officiis inibi fiendis et illas ac illa cantare adiuuando ut fidelis et deuotus christianus et diachonus predictus» (f. 1v).

17 La Lex Cornelia de sicariis es encuentra en el Digesto, 48.8, y la Lex Iulia maiestatis en el Digesto 48.4. No hay acusación en este proceso de rompimiento de Paz y Tregua (en cuyo caso no podía actuarse de oficio, como así fue en el presente juicio); aunque este se sancionó con la pena de lesa majestad (regulada por las dos leyes antedichas, especialmente la segunda) en la Constitución de Fondarella, de Alfons I, 1173, Vias publicas: «pena lese maiestatis inminente ei qui contrafecerit».

18 De Sori fue relevado de su procuraduría en la Corte del vicario, debido a su avanzada edad, en virtud de un nombramiento de Alfonso V, emitido desde la Gaeta el 22 de febrero de 1442 a favor de Narcís Franch (Romano, 1984, pp. 45-46). Desvern figura como notario y ciudadano de la ciudad condal en el mismo interrogatorio que Perayerii (vid. supra) en las Cortes de Barcelona de 1431-1434 (caravyc XVIII, pp. 325 y 356 ). 
do Sant Dionís), el caballero Joan Desfar y Narcís Miquel. Vidal se alojaba en casa del zapatero Antoni Oró y había llegado a la ciudad condal 15 días antes de Navidad (f. 3r). La vigilia de Navidad cenó con Antoni Oró a las ocho y después fue a la Plaça Nova, donde pretende haber tenido un encuentro imprevisto con Bernat Sarriera, acompañado de algunos campesinos, y haberse ido después a pasear por la iglesia de Santa María del Mar. Se trasluce desde el principio en Narcís la bisoñez propia de la edad que lo lleva a delatarse gradualmente. De hecho, la pueril estrategia de su defensa será alegar presencia pero no participación.

En el segundo interrogatorio, se le pregunta ya más claramente si se encontró con Sarriera en casa de Bellit, el cual era, de acuerdo con otras deposiciones a lo largo del proceso, el maestro barbero para quien trabajaba el otro hermano, Franci. Tras varias evasivas y falsedades, confiesa por fin haber acompañado a Sarriera y a dos campesinos desde la Plaça Nova en dirección a la plaza sant Jaume. A medio camino torcieron por una calle que bajaba en dirección a Santa María del Pi, probablemente la conocida hoy como de Sant Sever; y en la esquina plausiblemente de la calle sant Honorat se apostó, dejando a los otros que avanzaran hasta una alhóndiga sita en la zona, que se ha documentado en el número 3 de dicha calle. No es fácil, de todos modos, precisar el lugar del asalto ${ }^{19}$.

En el tercer interrogatorio, el 8 de febrero, Narcís Vidal reconoce haberse cruzado, días antes de Navidad, en el camino de Gerona a Barcelona, algo más allá de La Batllòria, con el canónigo Narcís de Sant Dionís, que iba a Gerona al entierro de un hermano, a quien acompañaban Sarriera y, algo atrasados, Pere Vidal y Felip Santceloni. Sarriera emplazó a Narcís Vidal, sin explicarle el motivo, para la vigilia de Navidad en casa del mismo Sant Dionís, en Barcelona; y su hermano Pere le aconsejó que no se mezclara en los asuntos de Sarriera: «Bé sé per què us vol, mas face'n ell matex» (f. 8r). Narcís Vidal acudió a casa de Sant Dionís, el canónigo, en Barcelona, donde halló jugando a 'gresca' ${ }^{20}$ a su otro hermano Franci, a Joan Comelles (mercader que testifica más tarde) y a otros dos de escasa importancia. Antes de trasladarse al taller de su maestro zapatero, en el Born, su hermano Franci le explicó que lo que pretendía Sarriera era golpear a Joan de Palomar y le desaconsejó unirse al comando. Pero Narcís le contestó que cumpliría con la palabra dada, si bien tendría cuidado.

Aparte de otros incidentes que amenizan la declaración, como las breves conversaciones mantenidas con el canónigo Sant Dionís, recién vuelto de Gerona, que fungía como señor respetable y valedor en este círculo, la vigilia de Navidad ya es Pere Vidal quien informa a su hermano Narcís de los propósitos de Sarriera (f. $9 v$ ). Narcís salió de la casa de su maestro hacia las 8 llevándose un mandoble y se reunió con Sarriera en la Plaça Nova. Se acercaron a la casa del canónigo Sant Dionís, donde Sarriera y Pere Vidal intercambiaron algunas palabras que Narcís

19 «[...] ell deposant e lo dit Bernat Sariera ab los dits dos pagesos se partiren de la Plaça Nova amunt vers Sent Jachme e quant foren en lo carrer qui gira a la avallada del Pi per lo call lo dit Bernat Sariera dix a ell deposant que's posàs en un cap de aqueys carrers de qualsevolgués que ells se metrien aquent. E stant aquí ell deposant anave una amunt altra avall. E com anà avall donà-li de viares que sentís lo dit Bernat Sariera e los altres en un carreró ho alfóndech qui és aquí a mà dreta quan hom va avall» (f. 6v). En cuanto a la alhóndiga, véase Fumanal Pagès et al. (2011). Es necesario constatar que el trazado de las calles aledañas al antiguo call y de este mismo no varió ostensiblemente hasta los primeros grabados que se conservan (AHCB 20096, 2553 y 3018, respectivamente de los años 1697, 1740,1797). Asimismo los Quarterons de Garriga i Roca aún mantienen la planimetría del antiguo régimen, no demasiado modificada desde entonces en el lugar del crimen.

20 Juego de dados medieval, prohibido en numerosas ocasiones. Vid. DCVB, voz correspondiente. 
declara no haber entendido. Los tres pasearon hasta el taller de Bellit, en la Plaça Nova y, tras irse Pere, Narcís y Sarriera esperaron hasta las nueve a que Franci acabara su labor.

Después vagaron alrededor de la antigua plaza de l'Oli, donde se alojaban los dos campesinos que acompañaban a Sarriera, hasta que, cuando tocaban a maitines, aquellos salieron con lanzas de mano («manesques»), que, sin embargo, dejaron luego junto al taller de Bellit, porque Sarriera proporcionó a los campesinos dos bastones y se intercambió con Narcís la espada que este llevaba por una espada menor y un broquel. Después los cinco se pusieron al acecho en la mencionada esquina de las calles que conducían a Sant María del Pi, cerca de donde vivía Palomar. Tras el ataque, en el que Narcís Vidal decía no haber participado directamente, y la desbandada de unos y otros, Narcís se reencontró con su hermano Franci y los dos campesinos, sin más noticia de Sarriera. Se separaron y al día siguiente ( 25 de diciembre, Navidad) Narcís Vidal acudió por la tarde a casa del canónigo Sant Dionís, con el que habló en varias ocasiones, $\mathrm{y}$ al que intenta presentar en su interrogatorio como ignorante del asalto cometido. Alrededor de la hora de vísperas de ese día se encontraron, en el claustro de la catedral, los tres hermanos Vidal, más Joan Comelles y un muchacho del taller de Antoni Oró, donde vieron a Palomar, que durante un momento les miró, como reconociéndolos ${ }^{21}$. Narcís pasó la noche, junto con su hermano Pere, en casa de Narcís de Sant Dionís. Al día siguiente el canónigo preguntó a Narcís Vidal por el ataque a Palomar (del que había sido informado por Pere), que pareció desencantar a Sant Dionís, visto que su rival había asistido a maitines y vísperas sin mayor inconveniente ${ }^{22}$.

Reconoce asimismo que su hermano Pere Vidal le habló de una carta enviada por el vicario de Gerona, Narcís de Sant Dionís, a su tío el canónigo, en la que le avisaba del rumor que corría al respecto en aquella ciudad, que acusaba a los dos hermanos Francesc y Narcís Vidal de haber cometido dicho atentado. Se les aconsejaba acudir a Gerona, donde recibirían un salvoconducto ('guiatge'), que, se da a entender, les pondría a resguardo de la justicia ${ }^{23}$. Se anuncia ya el principal argumento esgrimido por el abogado Guillem Vidal contra la celebración del mismo juicio.

21 «E en assò lo dit micer Johan de Palomar stant en dret la porta de la canonge se girà devers ells e·ls havia mirats una stona, ja si hauria sospita d'ells entant com eren servidors del dit micer Narcís. E lavós lo dit Pere, frare d'ell deposant, dix a ell deposant que no se podien ymaginar que haguessin sospita d'ells. E ell deposant dix-li que havia vist parlar lo dit micer Johan de Palomar ab un jove dels seus mentre stave girat devers ell deposant e los altres damunt dits mirants-los. E lo dit Pere, frare d'ell deposant, respòs e dis a ell deposant que $/ 13 \mathrm{r} / \mathrm{no} \cdot \mathrm{s}$ podia pensar per res que 1 dit micer Johan de Palomar los miràs per res d'axò, volent-ho dir del dit batiment» (ff. 12v-13r).

22 «E com vench lo sendemà de Nadal, qui és lo jorn de Sent Stheve, stant lo dit micer Narcís sobre taula demanà a ell deposant si havia vist lo dit micer Johan de Palomar. E ell deposant dix al dit micer Narcís que hoc, que ell deposant lo havia vist a vespres lo dia de nadal. E lo dit micer Narcís respòs a ell deposant dient que no 1 devien haver gayre tocat com tantost ere anat a matines. E ell deposant respòs al dit micer Narcís e dix-li que de bones li n'havían donadas e que ell deposant havia sentits los colps e que no podia ésser que no se'n dolgués. E lo dit micer Narcís respòs que a vegades desfreçaria hom moltes cosas per causa» (14v).

$23 \ll[\ldots]$ entorn tres setmanes pot haver [se sobrentiende primera quincena de enero], stant ell deposant en casa del dit micer Narcís [de Sant Dionís, canónigo], lo dit Pere frare d'ell deposant dix a ell deposant que·l dit micer Narcís havia haüdas letras de Gerona, las quals li havia aportadas un scuder del veguer de Gerona, ab las quals li fahia menció que a Gerona se comptave que havian batut micer Johan de Palomar e que ho hauria fet fer lo ardiacha, dient-ho del dit micer Narcís de Sent Dionís [a la sazón arcediano de Besalú], e que·s diria a Gerona que ho hauria fet ell deposant e lo dit Ffranci frare d'ell deposant. E que axí matex li fahia menció al dit micer Narcís que si ell deposant o lo dit Ffranci son frare ho havían fet que se n'anassen a Gerona e que aquí se metrien $\mathrm{ab}$ algun de sos nabots e que acordar-se hien e que serien guiats» (f. 14r). 
En el cuarto y último interrogatorio, en la misma Diputación, el lunes 10 de febrero, Narcís Vidal añadía, en cuanto al móvil de la agresión, que lo suponía relativo a la auditoría de cuentas de la Diputación ${ }^{24}$.

\subsection{Interrogatorios a Pere Vidal}

Seguidamente se procedió al interrogatorio del hermano de Narcís Vidal, Pere, que también pidió que le fueran leídos aquellos a que ya había sido sometido en la Diputación. En el primero, del día 7 de febrero, refiere las circunstancias previas a su detención, que se produjo el 6 al anochecer, dentro de la casa del mismo Sant Dionís, donde Pere vivía, tras ganarse en el escondrijo de un altillo. Más tarde revela que el mismo canónigo se encontraba en dicha cámara ${ }^{25}$. Pere alega desconocimiento sobre otros aspectos no muy honrosos para Sant Dionís, relativos a la ayuda que el canónigo debió de prestar a su doméstico para subir al escondite o a la acción de mantener cerrada la puerta de la cámara cuando el alguacil la empujaba ${ }^{26}$.

En ese primer interrogatorio y en otros dos sucesivos, el 7 y el 10 de febrero, Pere Vidal niega algunas de las declaraciones del hermano, pero presenta a sus inquiridores algunas escenas que sí resultaban contrastables. Aporta él mismo que Sarriera apareció por la noche a dejar en casa de Sant Dionís un manto ('clotxa') y le informó del apaleamiento (f. 22rv). Corrobora que se encontró con su hermano Narcís en el camino de Barcelona a Gerona, pero no recuerda que Narcís Vidal hablara con Bernat Sarriera (f. 23v). Añade también que la nochebuena anterior se encontró con Sarriera en la barbería de Bellit, y que iba acompañado por un muchacho y dos campesinos, pero la conversación no trató del inmediato ataque (f. 20v-21r); a hora de maitines fue al claustro de la Catedral, donde se paseó con el mercader Joan Comelles, hasta que volvió a casa de su señor, el canónigo Sant Dionís, para despertarlo, de modo que asistiera al oficio de maitines, y que se acostó (17r). Constata la veracidad de la escena del día siguiente, a vísperas, en el claustro, cuando Joan de Palomar reparó en los hermanos Vidal y en Comelles (f. 24v).

En relación al móvil, declara Pere que, días más tarde, estando con su señor Sant Dionís en casa del canónigo Formós y en presencia de otras dos personas, presumiblemente clérigos, alguien que pasaba por la calle advirtió a voces a algunos de los presentes, a modo de denuncia, que no se levantaran a maitines si no querían acabar apaleados como Palomar ${ }^{27}$. A esta manifestación, Sant Dionís respondió

24 «[...] que no ho sab ni ho ha hoÿt dir, bé és veritat que ell deposant presumex e és de intenció que lo dit micer /15r/ Johan de Palomar sia stat batut per rahó de l'offici que·l dit micer Johan té en la casa de la Deputació e que·1 dit micer Narcís sia stat greu com lo dit micer Johan té lo dit offici» (ff. 14v-15r).

25 «E dix que en un amagatay qui és en una privada de la dita casa qui respon en una recambra del dit micer Narcís e aquí ell deposant stava amagat. [...] és ver que lo dit micer Narcís era en la cambra, qui scrivie a la fenestra de la dita cambra» (f. 16rv).

26 «Interrogatus qui tanchà la porta de la dita cambra aprés que ell deposant se fou mès en aquella. E dix que no·s sab car ell deposant no feu sinó entrar en la dita cambra e metre's en lo dit amagatay. Interrogatus si ell deposant sab qui tania la porta tancada de la dita cambra de part de dintre aprés que ell deposant se'n fou entrat en la dita cambra car lo capdeguayte volia entrar en la dita cambra empanyent la porta d'aquella e no hi poch entrar. E dix que no·s sab» (f. 16v).

27 «[...] ell deposant ha hoÿt dir en aquesta forma, so és que ell deposant stant en casa de mossèn Fformós, canonge de Barchinona, però no li racorde qual jorn era, però bé sab que festa era aprés Nadal, en la qual casa era mossèn Pere de Palol, mossèn Busquets e lo dit micer Narcís de Sent Dionís e lo dit mossèn Fformós e companyes llurs e açò era vespre e ell deposant hoý que qui·s que fos cridant dix en la carrera semblants paraulas: «Oh 
jurando por la hostia sagrada no saber nada de aquel asunto ${ }^{28}$. Añade Pere Vidal de forma algo ingenua que ciertamente su señor tenía suficientes parientes y amigos que pudieran resultar responsables, y no ellos dos ${ }^{29}$. Aunque intenta ser más discreto que su hermano, Pere sí refiere las palabras del vicario de Gerona, Narcís de Sant Dionís, sobrino del canónigo, en una reunión mantenida en su casa (no se sabe si asistió a ella su tío), durante aquel viaje a la ciudad del Ter ya mencionado por Narcís Vidal (cf. antes f. 8r). El vicario Sant Dionís preguntó a Pere Vidal, en presencia de Bernat Sarriera, si Palomar se levantaba a los maitines que se oficiaban en la catedral. Cuando Vidal le respondió que no lo sabía, el vicario exclamó que así debía ser porque él tenía ya aprestados dos campesinos que acompañarían a Sarriera para apalear a Palomar ${ }^{30}$.

En cuanto al móvil de la agresión, Pere Vidal respondió de manera similar a su hermano ${ }^{31}$. Pero a la pregunta sobre si había oído de Narcís de Sant Dionís alguna palabra al respecto, responde que no, describiendo a su señor como taciturno y de carácter complejo ${ }^{32}$.

\subsection{Careo entre los hermanos Vidal}

El mismo lunes 10 de febrero, se confrontan las versiones de los dos hermanos alrededor de la breve conversación que mantuvieron en el camino de Gerona, cuando Pere intentaba disuadir a Narcís de involucrarse en los negocios de Sarriera. Pere reconoce por fin sus propias palabras, porque de hecho ya tenía noticias del plan que se fraguaba a través de una conversación anterior con Sarriera, durante un viaje previo que este había realizado a Barcelona. Vuelve, sin embargo, a cubrir las espaldas de su señor, negando que estuviera presente ${ }^{33}$.

mossèn Fformós, oh mossèn Costa, guardats que no·us levets a matines sinó batran-vos la squena axí com han fet a micer Johan de Palomar!»»» (f. 19r).

28 «[...] lo dit micer Narcís de Sent Dionís dix, parlant de las paraulas qui·s digueren com ell deposant era en casa del dit Fformós lo dit vespre, que ell havia trobat anuig e despler que tal cosa fos stada e que ell, dit micer Narcís, podie jurar salvament sobre la hòstia sagrada que no·n sabia res» (f. 19v).

29 «[...] ell deposant dix al dit mossèn Narcís Miquel que·l dit micer Narcís havia prou parents e amichs qui ho podien haver fet e que no·n calia inculpar nosaltres» (f. 19v).

30 «No porà ésser que la nit de Nadal ho les festes de Nadal no·s leu a les matines car en Bernat Sariera deu anar a Barchinona la nit de Nadal e jo hi he haüts dos hòmens qui se n'iran ab ell e abastoneran lo dit micer Johan de Palomar» (f. 24r).

31 «[...] que ell deposant se presumex que és stat batut per rahó de l'offici que ha en la casa de la Deputació de oÿdor de comptes» (f. 25r).

32 «Interrogatus si ell deposant ha hoÿt dir al dit micer Narcís que lo /25v/ dit micer Johan li havia feta descortesia ho despler com lo dir micer Johan hauria acceptat lo dit offici. E dix que no, dient més que lo dit micer Narcís és molt secret e molt suffisticat en si matex que no·n sab hom sinó las cosas que ha a dir a hom» (f. 25r-v).

33 «Mossèn, ver és que lo dit Bernat Sariera davia tornar ací en Barchelona altre vegada. E yo diguí-li: «e per què?». E lo dit Bernat Sariera dix-me: «bé ho sabreu». E jo diguí-li: «bé ho podeu dir a mi». E lo dit Bernat Sariera llavós dix-me: «Jo dech tornar ací en Barchelona alre vegada per batre micer Johan de Palomar». E per aquesta rahó yo diguí a Narcís Vidal las dites paraules so és saber: «Bé·m pens per què·t vol, mas fasse-u ell matex». Interrogatus hon eren ell deposant e lo dit Bernat Sariera com lo dit Bernat Sariera dix a ell deposant las dites paraules. E dix que en la sala de la casa del dit micer Narcís en Barchelona, que staven a la fenestra racolsats» (f. 27r). 


\subsection{Ulteriores diligencias: el 'guiatge' y otros testimonios}

Guillem Vidal, abogado de Narcís Vidal, interpuso el día 11 de febrero una cédula que mencionaba un salvoconducto otorgado por el mismo Guillem de Bordils, y alegaba el amparo del usatge Quoniam per iniquum principem $^{34}$.

El día 14 de febrero se procedió a interrogar a Joan de Comelles, también asistido como 'curator' por Guillem Vidal. Dicho Comelles había acompañado en el claustro a Pere Vidal a la hora de maitines, después se fue a dormir con una amada y por último volvió a casa del canónigo Sant Dionís, donde se acostó en una cama con Franci y Pere Vidal, además del escudero Miquel. Al levantarse, sobre las 10, Pere le narró la paliza, aunque, insiste, nada supiera de ella el canónigo Sant Dionís ${ }^{35}$.

Los días 17 y 18 de febrero nuevamente insitió Guillem Vidal, aduciendo sucesivas cédulas que reclamaban el mantenimiento del salvoconducto. Se nos informa de que dicho salvoconducto fue solo verbal y no escrito y en consecuencia el escrito del abogado Vidal se enfrasca en minucias jurídicas, con las habituales citas del derecho común, la glosa y la legislación propia (ff. 31r-34r), quizá aconsejado por el canónigo Sant Dionís (como se ha dicho, doctor en derecho civil) ${ }^{36}$.

No parece que diera respuesta la Corte del vicario. Procedió al interrogatorio, dos días más tarde (20 de febrero), de la señora Constança, mujer de Ivó Torró, de cuyo testimonio solo interesa la voluntad que la Corte del vicario muestra en averiguar, aunque sin éxito, el grado de implicación del mismo canónigo (ff. 34r-35r). Ese mismo día se volvió a interrogar en la misma Corte a Pere Vidal sobre las circunstancias en que se enteró de la noticia de la detención de su hermano y la reacción del canónigo Sant Dionís. Revela Pere que conoció el hecho por un mozo del taller del patrón de Narcís Vidal, el cual llegó hasta casa de su amo e informó de ello en el salón principal. Después el canónigo fue a ver al vicario. Se inquiere de manera directa, de nuevo, si colocó los bastones en la Plaça Nova, los que se usaron a posteriori en el ataque, a lo que responde no saber nada de los mismos (ff. 35r-36r).

El martes 25 de febrero, insistía Guillem Vidal en la observancia del salvoconducto y, en cualquier caso, en obtener copia de las instancias. El vicario le otorgó lo

34 Ff. 27v y ss. El salvoconducto, llamado 'guiatge', estaba sujeto a un buen número de supuestos determinados por la legislación catalana, que se inicia con los Usatges (Valls i Taberner; Abadal y Vinyals, 1985). El mencionado usatge prescribía que el Príncipe de Cataluña (rey de Aragón) no podía desamparar al beneficiado. Pero las Constituciones limitaban el poder de esta concesión real (vid. el mismo Compendium, Sant Dionís, 2016, libro 1 y rúbrica 13).

35 «Trobaren que·n Bernat Sariera ab dos pagesos hi és stat e han batut micer Johan de Palomar e son-hi stats Narcís Vidal e Ffranci Vidal, mos frares, e sab-me greu com los m’i ha mesclats». A lo que Comelles preguntaba: «Sap-ne res micer Narcís?». Y Pere Vidal respondía: «que may li n’havia hoÿt dir res ni sabia que·n sabés res lo dit Pere «ni yo (dient-ho del dit Pere Vidal) no hoý parlar sinó al vaguer de Gerona e an Bernat Sariera»»» (f. 30r).

36 Sirvan de botón de muestra los dos primeros puntos del escrito del 18 de febrero, en que menciona el Digesto, el Código, las Novelas, la glosa ordinaria (f. 31v; aclaramos entre llaves las referencias): «Primo quod dictus Narcissus Vidal est guidatus uerbo per dictum uicarium quod guidaticum ualuit et ualet ut in $\S$ Si uero et Neque autem De mandatis principum coll. III ibi sub nuncupa[to uer]bo feceris \{Nov. 17,6 y 7\}, quia tantum ualet fides uerborum data quantum cum scriptura ut $l$. pactatum quod bona fide C. De pactis \{CJ. 2,3,17\} cum ibi notato per Baldum. Secundo quod dictus Narcissus ex quo fuit et est guidatus non debet inquietari nec molestari iudicialiter quia fiducia data tenenda est iuxta notam per glo[ssam] et Bar[tolum] in his qui reus ff de publicis iudiciis $\{$ D. 48,1,5pr $\}$ et de non molestando probat textus in l. I C. De nauiculariis $l i^{\circ} X I^{o}$ \{CJ. 11,2,1\} cum ibi notato per Nicholaum de Neapoli et per Dionisium in dicto $\S$ Si uero et $\S$ Neque in autem De mandatis principum III collacione \{Nov. 17,6 y 7\} et in Vsatico Quoniam per iniquum et quod ibi scribunt iurisperiti Cathalonie». 
segundo y le dio día, el próximo jueves 27, para sus alegaciones contra el proceso (ff. 36r-36v). No fue, sin embargo, hasta el lunes 3 de marzo cuando Guillem Vidal aportó un salvoconducto del 12 de diciembre de 1426, concedido en Liria por el rey, que concernía a un tal P. Sarriera ${ }^{37}$ (el nombre de pila figura en esta copia siempre con la inicial, seguramente igual que en el original, donde quizá fuera fácilmente confundible o reinterpretable como B., es decir Bernat, de modo que la ambigüedad le resultase siempre favorable), los hermanos Vidal y un tal Guerau Congost, en relación con una futura armada real. Dicho salvoconducto habría sido transmitido a Sarriera por un caballero denominado Jaume Alamany de Bellpuig, que además, 1lamándose nuncio real, presentaba mediante Guillem Vidal una carta al vicario dando fe de ello y conminándole a obedecer. Inmediatamente el abogado Vidal aportaba la carta credencial, sellada con cera roja, que daba al caballero Bellpuig poder para extender el salvoconducto ${ }^{38}$.

El 4 de marzo Guillem Vidal aún aducía una carta que el caballero Bellpuig dirigía al vicario. En ella le explicaba las circunstancias de la decisión del tal P. Sarriera de participar en la armada real, así como la de otros hombres, los hermanos Vidal y Guerau Congost. No parece sino un plan del mismo Bernat Sarriera para conseguir amparo real frente al proceso. En dicha misiva, Bellpuig continúa explicando que supo después, por carta del mismo P. Sarriera, que Narcís Vidal estaba detenido y que si no se observaba el salvoconducto suponía un serio quebranto de la fe real, añadiendo que muchos de los comprometidos en la armada se desdecían inseguros de su propia suerte ${ }^{39}$. El abogado Vidal denunció en una cédula del día 5 la indefensión del reo, de la cual se enviaron copias respectivas a Antoni de Sori, procurador fiscal, y a Pere Gener, procurador de la Diputación ${ }^{40}$.

\subsection{Consulta jurídica sobre el 'guiatge' y parecer de Bonanat Pere}

Así las cosas, el vicario Bordils juzgó oportuno llevar a cabo una consulta jurídica, que se produjo el jueves 6 de marzo en casa de Bonanat Pere (licenciado en de-

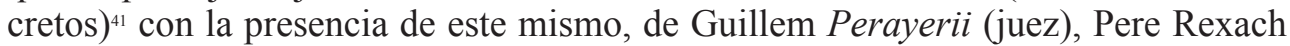

37 No sería extraño que las circunstancias en que se extendió el salvoconducto fueran ciertas, a pesar de las sospechas de la Corte (como se verá) y la evidente voluntad de los Vidal de utilizarlo para obtener inmunidad. De hecho, de la familia Sarriera, en una rama colateral a la de Bernat Sarriera, un tal Pere Sarriera figuró como capitán de navío en 1422 en una de las campañas italianas de Alfonso IV, si bien murió poco después (Miret i Sans, 1914). Algún otro miembro de los Sarriera bien pudo encontrarse en otra empresa similar en aquellas fechas.

38 «[...] quandam litteram regiam que fuerat ut per ipsam litteram missa clausa et sigillo secreto ipsius domini Regis in cera uirmulia imposito seu impresso ut primis uideatur aspectibus sigillatam» (f. 38r).

39 «[...] lo dit P. Sariera ha'm scrit com vós tanits pres lo dit Narcís Vidal per què·m raquer jo li fassa servar lo guiatge lo qual en nom del Senyor Rey li he donat. Axí matex molts d'altres qui han offert me n'an scrit sentintse d'assò per lur interès dient quax que si aquest Narcís és enganat en fe del Senyor Rey qu·ells no tendran les offertas» (f. 39v).

40 Sánchez de Movellán (2004, p. 225) registra que Pere Gener era escogido síndico del General el 14 de abril de 1423, pero probablemente no era aún procurador del General. La procuración de Ripoll se extendió todavía hasta mediados de 1426, como se ha dicho supra, y la de Gener debió de sobrevenir justo por aquellas fechas.

41 Se trata de una figura singularísima y de creciente relevancia en la medida en que se descubre su continuada participación en asuntos públicos tan señalados como las últimas Cortes del rey Martín I, siendo regente de la Cancillería a su muerte, más tarde como secretario de los compromisarios en Caspe, en sentencias de derecho público como la relativa a la convocatoria del Princeps namque, por parte de Fernando I (1413), en su papel como abogado del General o emisario del Consistorio (en momentos clave de la historia del Principado, como 
(abogado fiscal y doctor en leyes), Pere dez Coll (licenciado en leyes), y por último Francesc Castell (doctor en leyes). Resolvieron que se citara a testificar al caballero Bellpuig sobre las cartas y las circunstancias anexas y que a continuación el vicario consultara al rey sobre el particular, mientras que se sobreseía el proceso. El sábado 8 de marzo un sayón fue enviado a la Diputación para dar cuenta de la deliberación.

Ese mismo sábado, sin embargo, dos de los jueces consultados, Bonanat Pere y Pere dez Coll, presentaron al notario Antonio Desvern una cédula en que mostraban un cambio de parecer (ff. 41r-42v). De hecho, creían haber descubierto un fraude. Alegaba Bonanat Pere, y se adhería a ello dez Coll al final del escrito, que debía procederse con el juicio, considerados diez puntos. El primero aducía que la credencial real al caballero Bellpuig es «generalissima et nullam materiam explicat». Del segundo al cuarto ponían en duda la validez del sello y, podría decirse, la iussio regis correspondiente. El quinto alegaba que el llamado Pere Sarriera (esta vez el nombre de pila aparece in extenso, no cediendo a la ambigüedad) probablemente era uno de los denunciados, es decir, Bernat Sarriera, lo cual restaba mucha credibilidad a las circunstancias del salvoconducto. El sexto determinaba que el salvoconducto no podía beneficiar a Narcís Vidal, puesto que el crimen fue posterior. El séptimo presentaba que Narcís Vidal quedaba excomunicado por su acción y en consecuencia fuera de amparo; el octavo recordaba que ningún privilegio podía ser otorgado mientras hubiera un litigio pendiente; el noveno resaltaba que resultaba sospechoso que nunca antes Narcís Vidal hubiera hablado de ningún salvoconducto; y el décimo determinaba que había razón suficiente para proceder considerada la declaración del mismo reo.

El lunes 10 Guillem Vidal aportaba un instrumento que se insirió en el proceso, pero del que Antoni Desvern solo recoge el inicio (ff. 42v-43r). El 17 de marzo, otro abogado, Guillem Ferrer, como procurador de Narcís Vidal, presentó una serie de alegaciones capciosas de derecho común que se oponían a los puntos aducidos por Bonanat Pere y Pere dez Coll (ff. 43r-46r).

\subsection{Testimonios de la comitiva de Joan de Palomar}

El vicario no dudó en proceder con las diligencias al día siguiente, martes 18 , e interrogar a Joan Pallaga, mercader textil, que acompañaba la nochebuena del asalto a Joan de Palomar a maitines (ff. 46r-47r). El séquito lo componían cuatro: un muchacho que más tarde testifica, que iba delante con dos blandones, los que apagaron los atacantes ante todo, seguidamente iba Joan de Palomar vestido con una capa negra y detrás su escudero Pere Martí y el mismo Pallaga. Su testimonio habla de dos o tres hombres, el primero de los cuales con capacete («cervellera»), presumiblemente Sarriera y los dos campesinos, que los atacaron en una esquina donde había una alhóndiga. En lo demás solo añade que Palomar apretó a correr hacia la catedral. Después lo vio en la sacristía con la cabeza vendada y cómo más tarde iba hacia el coro, a maitines. En cuanto al móvil, la voz pública era clara y repetía lo mismo ya mencionado'².

la embajada a Jaime de Urgel, pidiéndole que depusiera su gobernación general en 1410, finado Martín I; o en 1418, a Alfonso V), en su desempeño como compilador de la Compilación de 1413 (Álvarez 2013, pp. 819821). A raíz al menos de este último encargo (si descontamos el trienio de 1416-1419, cuando fue abogado de la Diputación), debía de haber tratado a menudo a Sant Dionís. A partir de la segunda década del siglo XV Bonanat Pere es un jurista respetado y consultado con asiduidad.

42 «E dix que's diu comunament e pública per Barchelona que lo dit micer Johan de Palomar serie stat batut 
A continuación testificó Pere Durayer (ff. 47r-48r), el muchacho aludido, que viene a confirmar el anterior testimonio, pero detallando que el primer hombre (seguramente Sarriera) llevaba carrilleras con el capacete, broquel y espada ${ }^{43}$. De todos modos, no creía que le golpearan o agredieran más que con los bastones, que era lo que portaban los campesinos.

El testimonio del escudero Martí (f. 48v-49v) no aduce gran cosa más, aparte de un golpe con piedra que recibió en un brazo, y que los atacantes llegaron todos de una vez, no se añadió nadie más en un segundo momento, aunque bien pudieron ser unos cinco, lo cual incluiría ya a Franci y Narcís Vidal.

\subsection{Desestimación del 'guiatge' y cambio de jueces en la Corte del vicario}

El 22 de marzo el procurador fiscal Antoni de Sori desestimó el salvoconducto por las razones ya expuestas, citando asimismo la nota aducida por Bonanat Pere, inserta en el proceso (ff. $49 \mathrm{v}-50 \mathrm{v})$.

El 24 de marzo el vicario cambió inopinadamente de jueces y nombró a Francesc D'Ortals y a Pere Gerona, en sustitución de Guillem Perayerii (f. 50v). Guillem Vidal intentó oponerse dos días más tarde, el 26, insistiendo en que era contrario a derecho, de acuerdo con un consejo del consistorio de Barcelona, y debía mantenerse la primera resolución de sobreseimiento y consulta al rey (f. 50v-51v). El 27 de marzo el procurador fiscal, Antoni de Sori, pedía al vicario que procediera adelante y este consultaba a los consellers de Barcelona (Joan Ros, Jaume Bussot, Jaume Colom, Huguet Fivaller, Bernat Çapila) sobre el particular (ff. 51v-53r). Dichos consellers respondieron que no obstaba la deliberación previa y que debía seguirse con las diligencias que el vicario considerara oportunas para el juicio.

Ante la deriva que este tomaba, Guillem Vidal interpuso una reclamación que instaba a consultar a dos jueces. A pesar de que en un primer momento se inició otro interrogatorio a Narcís Vidal, el vicario decidió interrumpirlo a medias y remitió consulta a dos nuevos jueces, Bonanat de Puigmarí y Francesc Castell. Al renunciar expresamente este último fue substituido por Gabriel de Pere. Pospusieron su deliberación para un día más tarde, el 28 de marzo. Tal día condenaron a las costas de la reclamación, desestimándola, a la parte de Narcís Vidal (ff. 53r-56v).

\section{8. Último interrogatorio a Narcís Vidal y sentencia}

Así las cosas, el 29 de marzo se produjo una escena dramática. Al seguirse con el interrogatorio en el mismo punto en que se dejó, Narcís Vidal no quiso colaborar. Se le preguntaba sobre las contradicciones en que incurría respecto del lugar donde se encontraba en el momento del ataque, si al cabo de la calle o en dirección a la canonja (aunque es difícil determinarlo, parece tratarse, respectivamente, de la plaza Sant Jaume y de la actual puerta del claustro o de la Pia Almoïna). Mientras tanto su abogado, Guillem Vidal, insistía al vicario en la observancia del salvoconducto y en la consultoria al rey; y por otro lado el procurador fiscal Antoni de Sori le instaba

per l'offici que ten en la casa dels deputats de Cathalunya e que ho haurie fet fer micer Narcís de Sent Dionís canonge de Barchelona» (f. 47r).

43 «[...] lo dit hom isqué del dit alfóndech ab cara feréstega e vench vers ell testimoni e apagà-li los dits brandons» (f. $47 \mathrm{v}$ ). 
a proseguir (ff. 56v-57r). Guillem de Bordils conminó a Narcís Vidal a responder bajo amenaza de tortura, la cual finalmente se produjo. Lo tumbaron sobre un banco y le estiraron con cuerdas los brazos, puestos a la espalda ${ }^{44}$. Finalmente confesó que se encontraba en dirección a la canonja y que si respondió antes otra cosa fue por situarse lo más alejado posible del lugar del ataque.

Tras varios días de ausencia, Guillem Vidal acudió nuevamente al juicio, el 7 de abril, para presentar otros tantos artículos que porfiaban en la validez del salvoconducto. Los consellers de la ciudad antedichos de nuevo aconsejaron al vicario que no admitiera los artículos. El mismo día los jueces y los consellers decidieron entre varias penas posibles la de ahorcamiento. El día 9 de abril Pere Torró, notario de la Diputación, y con poder procuratorio, pidió copia de la inquisición. Y ahí concluye el proceso propiamente dicho (ff. $58 \mathrm{v}-65 \mathrm{r}$ ).

\section{Segundo proceso: G-193-4}

El segundo documento del que debe hablarse es el que contiene el proceso por rompimiento expreso de Paz y Tregua contra Narcís de Sant Dionís vicario, Bernat Sarriera y Francesc Vidal. La querella la presentó Pere Turró ${ }^{45}$, notario de la Diputación con poder procuratorio, el 10 de abril de 1427 ante el mismo vicario, Guillem de Bordils. Contiene los giros habituales: «diabolico spiritu inducti», haciendo hincapié en el hecho de que los asaltantes se pusieron en aguayt e incurrieron por tanto en sacrilegio, cometiendo uim publicam e iniuriam. Al mismo tiempo se había agredido al propio General en la figura de Palomar, se decía, por ser oidor de cuentas, y porque las agresiones se llevaron a cabo precisamente por haber aceptado este cargo. Es decir, se establecía una ilación rigurosa para que la Diputación pudiera presentarse como parte denunciante ${ }^{46}$. Se reclamaban 10.000 libras por la injuria y 5.000 por los daños al General. El vicario, de acuerdo con la ley, moderó estas cantidades a 5.000 y 2.000 respectivamente ${ }^{47}$. Es muy relevante el modo de proceder de la Diputación,

44 «Et in continenti dictus honorabilis uicarius de consilio dictorum uenerabilium iudicum siue inquisitorum mandauit sagionibus qui ibi erant quod expoliarent dictum Narcissum Vithalis ipsumque torquerent taliter quod responderet super hiis de quibus interrogatus extitit super quibus non curauit nec uoluit dare responsum. E encontinent los saigs qui aquí eren despullaren lo dit Narcís Vidal delat e descalsaren-li los sandals e abocaren-lo sobre un banch e giraren-li los brassos apart detràs ab cordes de cànyem. E aprés materen-li una corda de cànyem en los brassos en una dobla. E abans que tirassen les cordas fou interrogat per los dits honorables vaguer e jutges que respongués en so de què era interrogat. E dix que no respondria ni diria res. E més fou interrogat lo dit delat hon era ell deposant com lo dit batiment se féu. E dix que ell deposant no era en nagun loch. E aprés los dits saigs actès que lo dit delat no volia respondre $a b$ garrots un dessà, altra dellà comensaren de tirar las dites cordes. E lo dit Narcís Vidal comensà cridar moltes vegades: «Verge Maria, ajude’m! Verge Maria de Mont/58r/ serrat! Yo us ho diré, mesquí, pengau-me»») (ff. 57v-58r).

45 Figura como escribano en las nóminas de la Diputación; véase Sánchez de Movellán (2004, p. 192).

46 «omnes deputati et auditores compotorum fuerunt iniuriati ex dictis percussionibus et uulnera illatis in persona dicti honorabilis Iohannes de Palomar, auditoris compotorum officialis Generalis et partis corporis queque fuerunt illi fuerunt illi illate occasione eleccionis de illo facte ad illud officium et inmitu dicti officii et ex eo quia dictus honorabilis Iohannes officium dictum $/ 4 \mathrm{v} /$ auditoris compotorum acceptauit et ipsum exercuit et exercet quam iniuriam dicti domini deputati et auditoris compotorum nomine dicti generalis et officii quod gerunt tam nomine domini Regis quam totius principatus Cathalonie» (f. 4rv).

47 La querella sigue la normativa aprobada al respecto y asimismo procederá el juicio. El querellante debía proponer una enmienda que el vicario quizá moderaría. A continuación el vicario citaba a los querellados y tras quince días de plazo se los declaraba contumaces, se hacía pública su expulsión de paz y tregua y se doblaba la multa. 
que se presentó como parte en el juicio, y sin duda debió de sentar precedente, si bien no contamos con documentos que lo certifiquen.

\subsection{Cartas citatorias y respuesta del vicario Sant Dionís}

Tras la asunción de la querella, Bordils instituyó jueces de instrucción a Pere Gener i a Francesc d'Ortals. Seguidamente, se expidieron cartas monitorias o citatorias, fechadas el jueves 10 de abril, a los tres acusados (ff. 22r-60r). Sant Dionís respondió el 16 de abril por carta (está fechada el 17, pero debe de haber un error: XVII ${ }^{\mathrm{a}}$ por $\mathrm{XVI}^{\mathrm{a}}$, porque el acta que la insiere en el proceso es del miércoles 16) que el vicario de Barcelona no tenía ninguna potestad sobre él y que solo podía ser citado a juicio por el rey, para lo cual alegaba un tratado sobre Paz y Tregua de un jurista poco conocido, Joan Cardót8. A continuación, por si lo anterior no fuera suficiente, con la carta se aportaban diversos testimonios tomados por el juez ordinario de Gerona, Pere Rafael, el 12 de abril (ff. 73v-107r). De entre los 14 testigos, cabe destacar el caballero Joan Margarit y el subvicario Nicolau Pere, quien certificaba haber visto a Sant Dionís desempeñar su oficio. La petición de testimonios inserta versaba sobre cuatro artículos, que intentaban afirmar la coartada del vicario para la vigilia y el día de Navidad anteriores, cuando se encontraba, no en la ciudad condal, sino en Gerona, donde ejerció y se paseó con su bastón de mando públicamente. La defensa de Sant Dionís pretendía zanjar así el asunto, como si su responsabilidad o culpabilidad dependiera solo de su participación física en el vapuleo.

\subsection{Intervención del abogado Dalmau de Sant Dionís}

Se personó entonces, el 17 de abril, como procurador y abogado defensor de los tres acusados el doncel Dalmau de Sant Dionís, padre del Narcís de Sant Dionís vicario, hermano de Narcís de Sant Dionís canónigo, y tío de Sarriera. En el proceso figura en alguna ocasión también Guillem Vidal, pero en segundo plano. Dalmau de Sant Dionís adujo cédulas de primera tonsura de Bernat Sarriera (1406) y Francesc Vidal (1412), amparándose en la Concordia del Cardenal de Cominges con la reina Elionor, de 1372, que remitía a los clérigos a la jurisdicción eclesiástica ${ }^{49}$.

Así lo explicaba al detalle el mismo Sant Dionís (2016, pp. 336-340, en el libro de Paz y Tregua párrafo 5, 8; 5, 12; 5, 15), citando Constituciones anteriores como la de Jaime I en 1228, In Christi nomine (ibídem, p. 310, libro de Paz y Tregua, párrafo 1, 19, 25).

48 "scitis constitutum esse de iure communi et patrie quod par in parem non habet imperium et per consequens $164 \mathrm{v} /$ uos non potestis in iudicium coram uobis uocare nos dictum uicarium regium qui parem et separatam iurisdictionem exercemus. [...] signanter uenerabilis Iacobi Cardo in octaua questione sui tractatus quod ille non debet conueniri nec potest offerri querela contra eum qui alias de iure communi conueniri uel in iudicio esse non potest quia quo $/ 66 \mathrm{r} / \mathrm{ad}$ hec processus pacis et treuge non exorbitat a iure communi com ergo nos dictus uicarius Gerunde qui sumus de maioribus officialibus regiis non possimus pro delictis seu aliis fore factis puniri uel conueniri seu alias trahi durante regimine uicari[at]us officii nisi per dictum regem» (ff. 64r-66r). Joan Cardó o Cardona es un jurisconsulto vicense del s. XIV del que no se conserva nada, al menos que se sepa, aunque fue estimado y citado por Jaume Callís en su tratado sobre paz y tregua (Brocà, 1909-1910, p. 485).

49 «Clerici soluti non possunt /109r/ trahi ad iudicium uicarii Regii seu alterius iudicis secularis occasione processus pacis et treuge nec per dictos uicarium seu officialem Regum secularem citari seu moneri» (ff. 108v-109r). Cf. Sant Dionís (2016: 346, libro de Paz y Tregua 5,38): «Presbiteri uel clerici soluti pro Pacibus et Treugis non possunt trahi ad iudicium uicarii uel alterius iudicis secularis». Este tipo de subterfugios debían de ser habituales: cabe compararlo con un proceso incoado en Barcelona en la jurisdicción real por 
Seguidamente, Dalmau de Sant Dionís contraponía una serie de defectos de forma al proceso. Aparte de tildar a los querellantes (los diputados) de «inimici capitales» de Bernat Sarriera, su escrito alega que no puede la Diputación presentarse como parte o acusación privada puesto que no es un cuerpo animado. Joan de Palomar no es súbdito del General y no puede pretenderse que la injuria haya sido infligida a esta institución por haberla padecido aquel ${ }^{50}$. Denuncia asimismo connivencia entre los consellers de Barcelona y la Diputación para recusar el salvoconducto a Narcís Vidal. Volvió a presentar asimismo el 23 de abril otra serie de impugnaciones de Sarriera que se añadían a las ya aducidas el 17 anterior. Se dice en ellas que un proceso de Paz y Tregua no se puede incoar de oficio, en virtud de la Constitución de Pedro III Item quod de cetero, y que en el actual proceso los diputados estaban participando como oficiales ${ }^{51}$.

\subsection{Expulsión de Paz y Tregua}

Cuando Pere Torró, el notario que actuaba en nombre de la Diputación, veía acercarse el término del plazo de quince días tras la citación de los acusados, instó en sucesivas ocasiones $(24,26,28,30$ de abril) al vicario para que procediera a declarar la exclusión de Paz y Tregua por contumacia de los mismos (ff. 175r-181r). No fue, sin embargo, el vicario Guillem de Bordils, sino el subvicario Joan Ferriol ${ }^{52}$ quien determinó el 2 de mayo que se pregonara al vicario de Gerona, a Sarriera y a Francesc Vidal como expulsados del amparo de las correspondientes Constituciones y quien desestimó la aplicación a este caso de la sentencia del cardenal de Cominges antedicha (ff. $182 \mathrm{v}-214 \mathrm{v})$.

Por fortuna, se cuenta en este paso del proceso con documentación contrastable, como es la relativa a las diligencias de la Diputación para poner sobre aviso a sus diputados locales y ordenarles perseguir a los tres acusados. La institución escribió, en fecha indeterminada posterior al dos de mayo de 1427, al diputado local de Perpiñán y obispado de Elna, Jaume Seguer, para que detuviera al vicario Narcís de Sant Dionís, a Bernat Sarriera y a Francesc Vidal, como expulsados de Paz y Tregua, continuando las pesquisas hasta el Rosellón y el Conflent ${ }^{3}$.

estupro, en 1377, del cual el reo parece haber escapado por remisión al oficial del obispo (López Rodríguez, 2014, pp. 137 y ss.).

50 «Tum quia Generale Cathalonie cuius nomine nituntur agere seu querelare non est corpus animatum et per consequens pro iniuria $/ 113 \mathrm{v} /$ si qua facta esset seu illata alicui singulari non posset querelare nec dicti deputati nomine Generalis actento maxime quod dictus Iohannes de Palomar est liber homo non subditus domino dicti Generalis nec dictorum deputatorum. Et per consequens ex parte Generalis non potest uere pretendi dampnum sibi iniuria datum » (f. 113rv).

51 «[...] addit eisdem excepcionem contra personas dictorum honorabilium Iohannis de Faro militis et Narcissi Miquel deputatorum Cathalonie Generalis tanquam processum impedientem scilicet quod ipsi deputati gerunt se pro officialibus et per consequens non possunt dare querelam pacis et treuge obstante capitulo facto $/ 170 \mathrm{v} /$ et firmato per dictum Regem Petrum tercium in quarta Curia Barchinone tenoris sequentis: Item quod de cetero querelam $[\mathrm{sic}]$ pacis et treuge non possit dari nisi ad instanciam partis non autem per procuratorem fischalem nec per quoscumque alios officiales uel personas nec eciam possit procedi ex officio» (f. 170rv). En cuanto a la Constitución mencionada, vid. Sant Dionís (2016, p. 336, libro de Paz y Tregua 5, 3), donde se especifica que solo podía actuarse de oficio cuando el rey lo determinara por daño infligido a extranjero en camino público o en espacios reales.

52 Se encuentra como subvicario de Guillem de Bordils el 23 de noviembre de 1426 en el acta notarial de designación de nuevos consellers de la ciudad (CPMB doc. 1122).

53 ACA, Generalitat, Cauteles i albarans, N-510, f. 103v, albarán de 28 de julio de 1428, por el pago de 50 florines de Aragón a dicho diputado local. El que fuera discípulo del propio canónigo Sant Dionís, y de su hermano 


\subsection{Duplicación de la multa y testimonios de la Diputación}

El 10 de mayo, Pere Gener, procurador de la Diputación, pedía el doble del monto de la querella, habida cuenta de la contumacia (ff. $214 \mathrm{v}$ y ss.), al mismo tiempo que presentaba una serie de diecinueve artículos que certificaban la ilación entre la elección de Sant Dionís anulada, el parentesco de este con los acusados, la agresión a la institución en la persona de Joan de Palomar y la damnificación que la Diputación habría sufrido consecuentemente en su operatividad. En los cuatro primeros artículos se subrayaba la planificación y la perpetración del ataque, con distribución de responsabilidades entre quienes mandaban la operación, quienes la dirigían y distribuían las armas y quienes ejecutaban la acción ${ }^{54}$, que se llevó a cabo habiéndose puesto al acecho ('aguayt'), contra un clérigo, Palomar, que acudía vestido religiosamente a maitines. Del artículo quinto al noveno se incidía en que la agresión también fue contra el General, en que su causa era la elección de Palomar en substitución de Narcís de Sant Dionís ${ }^{55}$, en que los sobrinos de este estuvieron implicados en el asalto y eran en buena manera mantenidos por su tío el canónigo ${ }^{56} \mathrm{y}$ en que la Diputación hubiera preferido pagar 10.000 libras a enfrentarse a tal situación. Puesto que, insistían los artículos del 10 al 15, la institución había tenido que aconsejarse a menudo sobre este asunto ${ }^{57}$, había cesado en el ejercicio de otras obligaciones inherentes ${ }^{58}$, había incoado procesos en diversos tribunales, desde el real al del vicario ${ }^{59}$, además de sostener los gastos correspondientes. Los últimos artículos, del 16 al 19, repetían que tras la citación hubo contumacia por parte de los acusados.

Los testigos que debían corroborar dichos artículos fueron prestando testimonio a partir del 15 de mayo (ff. $228 \mathrm{v}$ y ss.). A los primeros cuatro mercaderes de Bar-

Dalmau de Sant Dionís, Tomàs Mieres (II, 1621, p. 274, párrafo 29), narró más tarde en su Apparatus que el vicario de Barcelona expulsó de Paz y Tregua al vicario Narcís de Sant Dionís: «ut vidi de honorabili Narcisso de Sancto Dionysio, tunc Vicario Gerunde, qui per Vicarium Barcinone fuit eiectus a pace et treuga, \& pro tali publicatus, pro eo quod dicebatur, quod in civitate Barcinonae verberaverat honorabilem Ioannem de Palomar de[c]retorum Doctorem».

54 Artículo primero: «per uicum uocatum de Sancta Eulalia predicti querelati quilibet ipsorum, non uerendo uiolare pacem et treugam domini et principis, quidam ipsorum percuti seu iniuriari tractando ac mandando, aliqui ipsorum dirigendo et monendo et arma tribuendo, aliqui ipsorum manu et factu operando, et armis ac baculis percusserunt» (f. 219v).

55 Artículo noveno: «Item ponit et etc. quod factis dictis percussionibus et iniuriis et publicatis fuit fama publica scientes [sic] quod predicte percussiones et iniurie fuerint facte occasione predictarum [sic] elleccionis facte et [sic] dicto honorabili Narcisso canonico et oppe et mandato predicti honorabilis Narcissi militis et Bernardi ac aliorum querelatorum» (f. 223r).

56 Artículo séptimo: «[...] predictus honorabilis Narcissus miles et Bernardus Serriera sunt nepotes dicti honorabili[s] Narcissi cano/222v/nici et alimentati et sustentati maiori parte temporis de bonis et redditibus dicti honorabilis Narcissi canonici» (f. 222rv).

57 Artículo undécimo: «Item ponit quod dicti honorabiles deputati pro premissis et occasione promissorum inhiberunt quod plurima consilia cum diuersis in iure parti[bu]s et aliis uoccandi[s] per multa tempora super consequenda iusticia de illis qui dictas iniurias et percussiones intulerunt» (f. 223v).

58 Artículo duodécimo: «Item ponit quod tempore quo in premissis intendebant cessarunt posse intendere in actibus dicti generalis seu uoctare et propter hoc fuerunt inpediti in expediendo negocia generalis prefati» (f. 224r).

59 Artículo decimocuarto: «Item ponit quod causa ac occasione premissorum plures processus fuerunt incohati et instati incohari tam in Curia illustrissimi domini Regis quam in Curia domini uicarii dicte ciuitatis Barchinone quam in Curia ecclesiastica reuerendi domini patriarche quam aliis diuersis curiis» (f. 224v). Cabe notar que se habla de la corte del obispo de Barcelona, Francesc Climent Sapera, entonces patriarca de Jerusalén; aunque de este otro proceso no se sabe nada más. Según se desprende de un testimonio posterior (Pere Ramis, ff. 252r y ss.) Pere Vidal fue retenido primeramente en dicha corte. 
celona que testificaron (Bartomeu Vives, Lluís de Capelles, Nicolau Cantó, Joan Padrés) se les preguntó por el artículo séptimo, relativo al parentesco del vicario de Gerona y Sarriera con el canónigo. Capelles y Cantó acentuaron además la función de la casa del canónigo Sant Dionís como lugar de encuentro de sus sobrinos, entre otros $^{60}$. Otros testigos institucionales confirman otros artículos. El regent els comptes de la Diputación, Galceran de Mataró, certifica el undécimo, el duodécimo, el decimotercero (respecto de la cesación de los negocios del General) y el decimoquinto, relativo a gastos. ${ }^{61}$ El notario y escribano de la Diputación Pere Ramis corrobora con cierta cantidad de datos los artículos del once al quince ${ }^{62}$.

Entre los últimos testigos aducidos por la Diputación destaca sin duda el notario de esta institución Gaspar Vinyals (los otros fueron los mercaderes de Barcelona Pere Verdaguer, Bartomeu Dena y Rafael Ferrer), muy presente en la documentación coetánea, comisionado en multitud de causas, una de ellas relativa a la misma remoción de Sant Dionís del oficio de oidor de cuentas ${ }^{63}$. En respuesta a los artículos antedichos, Vinyals reconoce haber asistido a las reuniones que los diputados tenían al respecto (ff. $264 \mathrm{v}-270 \mathrm{v}$ ).

Al final de la ronda de interrogatorios, el 21 de mayo de 1427, el procurador del General Pere Gener presentaba al subvicario Joan Ferriol una cédula, inserta en el proceso, que pedía de nuevo la duplicación de la cantidad de la querella.

\subsection{Sentencia y desenlace}

El subvicario Ferriol dictó sentencia al día siguiente, 22 de mayo de 1427, condenando a Narcís de Sant Dionís al pago de 5.000 libras por la agresión y 2.000 por los daños a la Diputación, más la duplicación y las costas judiciales. Había prevalecido por tanto la doctrina según la cual la entidad que representaba al General podía presentarse como querellante ${ }^{64}$.

60 «[...] dixit que bé sab ell testis que los dits mossèn Narcís de Sant Dionís e Bernat Sa Riera són nabots del dit micer Narcís de Sant Dionís canonge e en lo temps que lo dit mossèn Narcís cavaller no havia muller revenia algunes de vegades en casa del dit micer Narcís vinent d'altres lochs. E axí matex ha vist ell testis /239r/ que lo dit Bernat Sa Riera com vania en Barcelona revania en casa del dit micer Narcís de Sant Dionís e segons fama tots los amichs del dit micer Narcís canonge han bon amich del dit micer Narcís [sic]. Interrogatus com sab ell testis que los dits mossèn Narcís de Sant /239v/ Dionís cavaller e Bernat Sa Riera sien nebots del dit micer Narcís canonge e dix que per tal com ell testis sab que micer de Dalmau de Sant Dionís [és] pare del dit mossèn Narcís cavaller e és germà del dit micer Narcís canonge. E la mare del dit Bernat Sa Riera muller de n'Arnau Sa /240r/ Riera era germana del dit micer Narcís canonge» (ff. 238v-240r, testimonio de Nicolau Cantó).

61 «Super $\mathrm{XV}^{\mathrm{o}}$ capitulo interrogatus et dixit so solament sobre: que ell testis qui hagut càrech de pagar los correus qui anaven per la dita rahó hi ha despesos de CC en CCC florins d'or d'Aragó los quals correus anaven axí al senyor Rey com en altres parts» (f. 248v). Galceran de Mataró aparece en diversos asientos del Diari de la Generalitat entre 1412 y estas fechas, cuando figura ejerciendo dicho cargo (Sans i Travé, 1994).

62 Sobre el artículo undécimo: «Interrogatus quomodo scit et dixit que per ço com ell testis pujà algunes jornades en les cambres del Consell de l'arxiu dels comptes de la casa de la Deputació e viu que los dits honorables deputats ço és los dos seglàs e a vagades los dos hoid[or]s de compta sengles eren ensemps en consell ab los advocats e altres juristes en la dita casa e cambres. E que en lo dit consell los dits dos deputats a vegades los $/ 253 \mathrm{r} / \mathrm{dits}$ dos hoidós ab ells parlaven dels dits affers jatsie ell testis no hoís res de lurs conclusions car no y atinava» (ff. $252 \mathrm{v}-253 \mathrm{r}$ ). Pere Ramis es el notario que escribe las cartas emitidas por la diputación durante el trienio: ACA, Generalitat, Escrivania Major, lletres trameses, N-641.

63 Sant Dionís (2016, p. 25, n. 45).

64 «Cum ex causa ex processu dicte inquisicionis [...] constet nobis dictum uenerabilem Narcissum iniuriasse ac dampnificase dictum /285v/ Generale Principatus Cathalonie et dictos uenerabiles deputatos nomine ipsius 
Por desgracia la sentencia obvia a Bernat Sarriera y a Francesc Vidal. Las actas del proceso dan un salto en el tiempo de varios meses hasta el 19 de septiembre de 1427. En el lapso cronológico intermedio, el caballero Sant Dionís (que ya habían dejado de ser vicario) y Sarriera habían sido detenidos, como se desprende de la comparecencia del procurador Pere Gener, el día mencionado, ante el vicario de Barcelona para presentarle una cédula que pedía el traslado de los dos presos a otras dependencias institucionales sin salir de la ciudad. Se procedía a elevar esta petición puesto que a los detenidos los respaldaban varios fiadores bajo pena de 10.000 florines $^{65}$.

Un mes más tarde, el 25 de octubre, el mismo Pere Gener presentó otra cédula que solicitaba la reducción a Paz y Tregua de Narcís de Sant Dionís puesto que había satisfecho «certam obligacionem», probablemente el monto de la querella (ff. 291v-292r). Inmediatamente, tras ser admitido el escrito de Gener, se personó el mismo canónigo Sant Dionís, como procurador de su sobrino, para aducir otra cédula que venía a requerir lo mismo ${ }^{66}$. Aunque nada pueda afirmarse, no sería descabellado suponer que la Diputación exigiera a la parte querellada esta comparecencia del canónigo Sant Dionís - responsable moral último del apaleamiento de Palomar y causante de tantos quebraderos de cabeza a la institución desde mediados de 1425para la feliz resolución del pleito al menos respecto de su sobrino homónimo.

Las actas aún recogen la letra del pregón que el 27 de octubre emitió por la ciudad condal el pregonero Bernat Cadireta (ff. 293r-295v). Aquí terminan las diligencias sin dar más noticia de la suerte de Bernat Sarriera ni de Francesc Vidal, que no parece haber sido detenido al menos en las mismas fechas. Seguidamente, como ya se ha dicho, Antoni Desvern firma y da fe notarial de la copia del proceso.

in quinque mille libras pro dampniis ex alia ideo per hanc nostram sentenciam de consillio dicti Petri Gerona adiudicamus dictas quantitates sicilicet quinque mille et duas mille libras una cum dupla diuidenda secundum consituciones Cathalonie racionibus predictis dicto Generali seu eius honorabilibus deputatis et ad dictas quantitates soluendas /286r/ ipsas dictum uenerabilem Narcissum de Sancto Dionisio militem condempnamus una cum expensis omnis processus» (ff. 285r-286r).

65 «Com vós molt honorable mossèn lo vaguer tingats presos en la presó comuna de la /288r/ ciutat de Barchelona a instància dels molt honorables deputats del General de Cathalunya los honorables mossèn Narcís de Sant Dionís cavaller domiciliat en la ciutat de Gerona e en Bernat Sa Riera fill de Arnau Ça Riera ciutedà de la dita ciutat e los dits senyors deputats hagen deliberat que prometen $/ 288 \mathrm{v} /$ que els dits dos presos sien arrestats en aquelles cases que ells elegiran en la present ciutat de Barchelona ab prestació de sagrament e homenatge e ab pena de déu míl·lia florins per cascun d'ells e ab bones fermanses per rahó de la dita pena per so en Pere Gener en nom e com a procurador dels dits senyors deputats vos notiffica que als dits senyors deputats $/ 289 \mathrm{v} / \mathrm{plau}$ tant com toch lur interés e del dit General que vós mossèn posets en lo dit arrest e en la forma demunt expresada lo dit mossèn Narcís de Sant Dionís e Bernat Sa Riera, ells emperò donans per fermanses los honorables mossèn Pere Palou canonge e Cabischol de la seu de Barchelona, lo noble Galceran de Santa Pau, mossèn Jacme /290r/ Viçens cavaller e Bernat Fivaller e en Francesch Ça tria et Petrus Busot, Francesch de la Via mercader e·n Luýs Capelles mercader, e·n Jacme Lopp specier, ciutedans de Barchelona e cascuns d'els in solum e per lo tot en los dits déu mília fflorins de pena com axí sia stat offert per part dels dits presos als dits honorables diputats requirent-vos en notari etc.» (ff. $287 \mathrm{v}-290 \mathrm{r}$ ).

66 «Et oblata predicta papiri cedula in continenti coram dicto honorabili uicario et dictis suis uenerabilibus in hiis assidentibus comparuit honorabilis Narcissius de Sancto Dionisio canonicus ecclesie Barchinone tanquam procurator et nomine procuratorio ut asseruit dicti honorabilis Narcissi de Sancto Dionissio militis et dicto /292v/ nomine obtulit et presentauit eidem quandam papiri cedulam scriptam [uidetur] tenoris sequentis: Cum multum honorabilis domini deputati generalis Cathalonie ad quorum instanciam Narcissius de Sancto Dionissio miles uicarius Gerunde fuit pro aiecto a pace et treuga publica[tus] et clamus adiudicatus sunt contenti de /293r/ dicto Narcissio et placet eis quod dictus Narcissius reducatur in pacem et treugam, ideo idem Narcissus suplicat et requirit uos multum honorabilem dominum uicarium Barchinone quatenus eumdem uelitis reducere in pacem et treugam cum sit de iusticia sic fiendum» (ff. 291r-293r). 


\section{Conclusión}

Como breve recapitulación de cuanto se ha recogido en este trabajo, cabría insistir en el revuelo que la acción de Sant Dionís provocó en la Diputación, cuyo carácter de garante político de la observancia había surgido en las Cortes de Barcelona de 1413 y había sido corroborado por la reina María solo a principios de la misma década, en 1422, con la Constitución Lo fruït de les lleis. La Diputación estaba consiguiendo algunos éxitos notables en su nuevo papel frente al monarca, además de proveerse de la Compilación, que contenía los derechos y las leyes generales y parecía preservarlos de modo inquebrantable. Por último, tras la experiencia fallida del cuerpo de seis inquisidores que velaran por la legislación del Principado, la Diputación se dotó de un procurador en 1422, Bartomeu Ripoll.

Sant Dionís había sido oidor de cuentas (1416-1419), compilador de aquella misma Compilación (1419-1422 aproximadamente), miembro del cuerpo de inquisidores mencionado (1420-1422) y volvía a ser oidor de cuentas en 1425 cuando parece que cayó en desgracia y fue expulsado fulminantemente del colegio de oficiales de la Diputación. Por razones que conviene estudiar, el procurador Ripoll era comisionado por aquella para que defenestrara políticamente en un proceso correspondiente a una figura cada vez más consolidada, como era Sant Dionís, al cual no amparaba tampoco la apelación al monarca, en cuyo círculo había medrado y se había armado caballero su sobrino Narcís de Sant Dionís, a la sazón vicario real en Gerona. Este cúmulo de circunstancias debe de haber pesado tremendamente en la maquinación del futuro asalto a Palomar y no parece que la Diputación errase o exagerase al presentarse como víctima de una agresión, sentando probablemente precedente.

\section{Bibliografía}

\subsection{Fuentes manuscritas o gráficas}

$\mathrm{ACA}=$ Archivo de la Corona de Aragón:

Generalitat, Processos judicials seguits davant el Consistori etc., Sèrie G-232.

Generalitat, Processos judicials seguits davant el Consistori etc., Sèrie G, 193,4.

Generalitat, Escrivania Major, lletres trameses, N-641.

Generalitat, Cauteles i albarans, N-510.

AHCB $=$ Archivo Histórico de la Ciudad de Barcelona:

GARRIGA I ROCA, Miquel, Quarterons (c. 1840). [Consulta en línea, durante el junio de 2017, en la página: < http://darreramirada.ajuntament.barcelona.cat/ > ]

Grabado 20096 [Barcelona, 1697].

Grabado 2553 [Barcelona, 1740].

Grabado 3018 [Barcelona, 1797].

Llibre del Consell, 02.01/B.I-29.

\subsection{Bibliografía impresa}

Álvarez Gómez, Daniel, «Els testaments del jurista Narcís de Santdionís (1458) i del seu germà Dalmau (1432)», Cuadernos de Historia del Derecho, XIX, 2012, pp. 233-255. 
— «Final de les Corts de 1413. Edició del memorial del 6 de setembre», Initium, 18, 2013, pp. 803-830.

- El Compendi de Narcís de Sant Dionís a la Compilació de les Constitucions de Catalunya (1413-1422), tesis doctoral, dirección de Espluga Corbalan, Xavier, Universitat de Barcelona, Barcelona, $2015^{1}$.

— «El gerundense Dalmau Gabriel de Sant Dionís, obispo de Siracusa (1469-1511)», VI Congreso Internacional de Humanismo y Pervivencia del Mundo Clásico. Homenaje al profesor Eustaquio Sánchez Salor, Alcañiz, 19 al 24 de octubre de $2015^{2}$.

Brocà, Guillem M. de, «Juristes i jurisconsults catalans dels segles XIV-XVII», Anuari de l'Institut d'Estudis Catalans, 3, 1909-1910, pp. 483-515.

caravyc [más el núm. del vol.] = Real Academia de la Historia, Cortes de los antiguos reinos de Aragón y de Valencia y principado de Cataluña, Real Academia de la Historia, Madrid, 1896-1922.

DCVB = Alcover, Antoni M.; Moll, Francesc de Borja, Diccionari català-valencià-balear: inventari lexicogràfic $i$ etimològic de la llengua catalana en totes les seves formes literàries $i$ dialectals, Editorial Moll, Palma, 1993. [en línia por la digitalización del Institut d'Estudis Catalans: < http://dcvb.iecat.net/ > . Data de consulta: primer semestre de 2017.]

Elías de Tejada, Francisco, Las doctrinas políticas en la Cataluña medieval, Ayma, Editor, Barcelona, 1950.

Ferro, Víctor, El Dret Públic Català. Les institucions de Catalunya fins al Decret de Nova Planta, Eumo Editorial, Barcelona, 1999.

Fumanal Pagès, Miquel Àngel et alii, «Documentant l'arqueologia: la casa de Massot Avengenà a l'alfòndec del call Major de Barcelona (carrer de Sant Honorat, num. 3)», Tamid: Revista Catalana Anual d'Estudis Hebraics, 7, 2011, pp. 9-71.

Guilleré, Christian, Gerona al segle XIV, traducción de Mañé, Núria, vol. 1, Ajuntament de Gerona, Publicacions de l'Abadia de Montserrat, Barcelona, 1993.

- Gerona al segle XIV, traducción de Mañé, Núria, vol. 2, Ajuntament de Gerona, Publicacions de l'Abadia de Montserrat, Barcelona, 1994.

- «Une famille de médecins geronais au XIVE siècle: les Sarriera», Acta historica et archeologica mediaevalia, 26, 2005, pp. 677-691.

López Rodríguez, Carlos, Sexe i violència a la Corona d'Aragó, Universitat de València, Fonts històriques valencianes, València, 2014

LQS = Libre dels Quatre Senyals, del General de Cathalunya. Contenint los diuersos Capitols de Corts, Ordinations, declarations, priuilegis, y cartas reals fahents per lo dit General. Manat estampar essent Deputats del dit General los molt illustres Senyors don Garci Gil Manrrique olim de Gerona, y despres bisbe de Barcelona, D. Phelip de Sorribes i Sarrouira, y Anthoni Axada ciutada honrat de Gerona. Y Oydors de comptes Onofre Ciurana y de Bellafilla, canonge de la Seu de Gerona, don Ramon Sabater, y lo doctor Ioseph Maso ciutada honrat de Barcelona. Any 1634. En Barcelona: de manament de ses Senyorias; en casa de Hieronym Margarit. Barcelona, 1634.

Mansi, Joannes Dominicus, Sacrorum conciliorum nova et amplissima collectio. [...] XXIX. Venetiis: Apud Antonium Zatta. Venecia, 1788.

-Sacrorum conciliorum nova et amplissima collectio. [...] XXX. Venetiis: Apud Antonium Zatta. Venecia, 1788.

Mieres, Tomàs, Apparatus super Constitutionum Curiarum Generalium Cathaloniae, per Thomam Mierem in decretis licentiatum et jurisperitum gerundensem editi, etc. Pars prima / pars altera. Barcinonae: Typis, et aere Sebastiani a Cormellas, anno 1621. Barcelona, 1621. 
Miret i Sans, Joaquim, «Els Sarrieres, senyors de Solterra i Sant Hilari», L'Estiuada, Sant Hilari Sacalm, VII, 77, 7 agosto 1914, p. 1.

Perarnau, Josep, Felip de Malla. Correspondència política, edición de Perarnau, Josep, volumen 1, Editorial Barcino, Barcelona, 1978.

Rexach, Albert, Municipi, finances $i$ elits locals en una ciutat catalana baixmedieval: Girona (1345-1445), tesis codirigida por Orti Gost, Pere; i Verdés Pijoan, Pere, Universitat de Girona, Gerona, 2015.

Romano, «Quin Narcís Franch fou traductor del «Corbaccio»?», Butlletí de la Reial Acadèmia de bones Lletres de Barcelona, 39, 1983-1984, 1984, pp. 5-62.

Sanchez de Movellán Torent, Isabel, La Diputació del General de Catalunya (1413-1479), Institut d'Estudis Catalans, Barcelona, 2004.

Sans i Travé, Josep Maria dir., Dietaris de la Generalitat de Catalunya, volumen 1, Generalitat de Catalunya, Barcelona, 1994.

— dir. Catàleg de pergamins del fons de l'ajuntament de Girona (1144-1862), 2 volúmenes, Arxiu Municipal de Girona, Fundació Noguera, Barcelona, 2005.

Sant Dionís, Narcís de, Compendium Constitucionum Generalium Cathalonie, Edición de Álvarez Gómez, Daniel, volumen 36 de la Col·lecció Textos Jurídics Catalans, Parlament de Catalunya, Departament de Justícia, Barcelona, 2016.

Valls i Taberner, Ferran; Abadal y Vinyals, Ramon d', Los Usatges de Barcelona, Promociones Publicaciones Universitarias de Barcelona, Barcelona, 1985 